\title{
Comparison of P-53, Ki-67 and Cd-10 Expression Between Fibroadenoma, Benign Phyllodes Tumor and Malignant Phyllodes Tumor
}

\author{
Challa Sukumar ${ }^{1}$, Shakti Kumar Yadav, Garima Singh ${ }^{1}$, Sompal Singh ${ }^{1}$ and Namrata Sarin ${ }^{1 *}$ \\ ${ }^{1}$ Department of Pathology, North Delhi Municipal Corporation Medical College and Hindu Rao Hospital, Delhi, India \\ ${ }^{2}$ Department of Pathology, All India Institute of Medical Sciences, New Delhi
}

\begin{abstract}
Background: Fibroepithelial tumors of the breast are a heterogeneous group of biphasic lesions comprising of an epithelial component and a quantitatively predominant mesenchymal component. These are classified into two major categories: Fibroadenoma and phyllodes tumor (PT). Phyllodes tumors are classified into benign, borderline and malignant grade categories based on histological parameters.

Methods: An analytical-cross sectional study was conducted in the Department of Pathology, Hindu Rao Hospital, Delhi-110007 from November 2016 to December 2018. Total 50 cases were included in the study comprising of 30 cases of fibroadenoma, 15 cases of benign phyllodes tumor and 5 cases of malignant phyllodes tumor. All specimens were fixed in $10 \%$ buffered formalin. Tissue were processed and embedded in paraffin. The sections were stained with hematoxylin and eosin (H\&E) to study the histopathological section. Immunostaining using CD-10, Ki-67 and p53 antibodies was done in all cases.
\end{abstract}

Result: Among fibroadenoma cases only 3.33\% showed positive CD-10 expression and 96.66\% were negative. CD-10 expression was positive in $26.67 \%$ cases of benign phyllodes while 73.33 showed negative expression. $40 \%$ malignant phyllodes cases showed positive CD10 expression and $60 \%$ showed negative CD-10 expression. CD-10 expression was significantly higher in benign phyllodes $(\mathrm{p}$ value $=0.019)$ and malignant phyllodes ( $\mathrm{p}$ value 0.007 ) group as compared to fibroadenoma. P-53 expression in epithelium was seen in $56 \%$ of fibroadenoma and $26 \%$ of benign phyllodes cases, while all cases of malignant phyllodes tumor show negative P-53 expression. The stromal expression of P-53 was significantly higher in malignant phyllodes as compared to fibroadenoma and benign phyllodes tumor. Stromal expression of Ki67 was significantly higher in malignant phyllodes as compared to benign phyllodes and fibroadenoma. Epithelial expression of Ki-67 was negative in all malignant phyllodes cases while positive epithelial Ki-67 expression was seen in $56 \%$ of fibroadenoma and $33 \%$ of benign phyllodes tumor.

Conclusion: Both Ki-67 and P-53 showed a significantly increasing expression from fibroadenoma to benign phyllodes to malignant phyllodes tumor. The difference in expression of CD-10 was insignificant among fibroadenoma, benign phyllodes and malignant phyllodes tumor.

Keywords: Fibroepithelial Tumors, Fibroadenoma, Phyllodes Tumor

\section{Introduction}

Fibroepithelial tumors of the breast are a heterogeneous group of biphasic lesions comprising of an epithelial component and a quantitatively predominant mesenchymal component. These are classified into two major categories: Fibroadenoma and phyllodes tumor (PT) ${ }^{[1]}$ Fibroadenomas of the breast are benign tumors characterized by an admixture of stromal and epithelial tissue. Unlike typical lumps from breast cancer, fibroadenomas are easy to move, with clearly defined edges. ${ }^{[2]}$ The incidence rate of fibroadenoma peaks during the 20's, the highest rates occur in married nulliparae, but this is not so at higher ages ${ }^{[3]}$ Phyllodes tumor applies to mixed epithelial-mesenchymal lesions with often a foliated structure, a double layered epithelial component and an overgrowth of the stromal component. The latter shows increased cellularity and proliferative activity, or even a sarcomatous appearance. It is a rare tumor representing $2.5 \%$ of all fibroepithelial lesions of the breast and with incidence of $0.3-0.5 \%$ of female breast tumors. ${ }^{[4]}$ They may be considered benign, borderline, or malignant depending on histologic features including stromal cellularity, infiltration at the tumor's edge, and mitotic activity. ${ }^{[5]}$

In cancer biomarker studies, the neprilysin gene is often referred to as CD-10 or CALLA. In some types of cancer, such as metastatic carcinoma and some advanced melanomas, neprilysin is overexpressed, ${ }^{[6]}$ in other types, most notably lung cancers, neprilysin is downregulated, and thus unable to modulate the pro-growth autocrine signaling of cancer cells via secreted peptides such as mammalian homologs related to bombesin. ${ }^{[7]}$

CD-10 belongs to the metalloprotease family, its increased expression may facilitate the metastatic potential of highergrade lesions by providing tumors with the capacity to invade vessel walls. CD-10 expression seen in the stromal 
cells of invasive breast carcinoma was associated with an increased incidence of lymph node metastases. ${ }^{[8]}$

P-53 protein is an important transcription factor which plays a central role in cell cycle regulation mechanisms and cell proliferation control. In 1992 Lane $\mathrm{DP}^{[9]}$ proposed a hypothesis that p53 protein acts as a "guardian" of the genome - its activation protects the organism from tumorigenesis. DNA damaging agents induce the activity of this protein, which leads to cell cycle arrest in the G1 or G2 phase, and in the case of ineffective DNA repair apoptosis is initiated. ${ }^{[10]}$

The Ki-67 protein (also known as MKI67) is a cellular marker for proliferation. ${ }^{[1]]}$ It is strictly associated with cell proliferation. Inactivation of antigen KI-67 leads to inhibition of ribosomal RNA synthesis. ${ }^{[12]}$

In view of paucity of Indian literature and ambiguity in various studies of expression of these markers in fibroepithelial lesions of breast, the present study is planned to study the expression of P-53, Ki-67 and CD-10 expression in fibroepithelial lesions of breast.

\section{Materials and Methods}

Study was conducted in the Department of Pathology, Hindu Rao Hospital, Delhi-110007 from November 2016 to December 2018. The study was analytical-cross sectional study. Recurrent cases of phyllodes tumor will be excluded from the study. Total 50 cases were included in the study comprising of 30 cases of fibroadenoma, 15 cases of benign phyllodes tumor and 5 cases of malignant phyllodes tumor. Clinical details such as age and sex were noted. All specimens were fixed in $10 \%$ buffered formalin. Tissue were processed and embedded in paraffin. The sections were stained with hematoxylin and eosin (H\&E) to study the histopathological section. Slides were examined and detailed morphological features were noted.

Immunostaining using CD-10, Ki-67 and p53 antibodies was done in all cases. CD-10 expression in all cases was evaluated using a semiquantitative method in the stroma. P-53 and Ki-67 expression in all cases was evaluated using a semiquantitative method in the epithelium and stroma.

Statistical analysis was done to compare the stromal expression of CD-10 and both epithelial and stromal expression of Ki-67 and p53 in the fibroadenoma, benign phyllodes and malignant phyllodes tumor. The Chi-square test was used to determine the difference of CD-10, P-53 and Ki-67 expression between fibroadenoma, benign phyllodes and malignant phyllodes tumor. All statistical analyses were carried out using SPSS 23 (IBM, Armonk, NY, USA).

\section{Result}

The study was conducted at a tertiary care hospital, from November 2016 to December 2018. A total of 50 cases were included in the study. Histopathological examination of cases was done followed by immunohistochemical staining using CD-10, P-53 and Ki-67 antibodies. Brown cytoplasmic staining of CD-10 was observed in positively stained cells whereas brown nuclear and cytoplasmic staining of both p53 and Ki-67 was observed in positively stained cells.

Frequency distribution table was made for the clinical data of the patients. The mean age and sex were noted. Among the fibroadenoma cases, maximum number of cases $(66.67 \%)$ were in the age group of $10-20$ years while majority of cases $(53.33 \%)$ with benign phyllodes were in 21-30 years age group. However maximum malignant phyllodes cases $(80 \%)$ were in age group of $10-30$ years (Table 1).

Among fibroadenoma cases only $3.33 \%$ showed positive CD-10 expression and $96.66 \%$ were negative. CD10 expression was positive in $26.67 \%$ cases of benign phyllodes while 73.33 showed negative expression. $40 \%$ malignant phyllodes cases showed positive CD-10 expression and $60 \%$ showed negative CD-10 expression. CD-10 expression was significantly higher in benign phyllodes $(\mathrm{p}$ value $=0.019)$ and malignant phyllodes $(\mathrm{p}$ value 0.007 ) group as compared to fibroadenoma. (Table 2 $\&$ figure 1,2) However, the difference of CD-10 expression between benign phyllodes and malignant phyllodes was not significant.

Expression in stromal cells was positive in $60 \%$ malignant phyllodes cases. While majority of cases of fibroadenoma and benign phyllodes showed negative P-53 expression in stroma. The stromal expression of P-53 was significantly higher in malignant phyllodes as compared to fibroadenoma and benign phyllodes tumor.

P-53 expression in epithelium was seen in $56 \%$ of fibroadenoma and $26 \%$ of benign phyllodes cases, while all cases of malignant phyllodes tumor show negative P-53 expression in epithelium. The epithelial expression of P-53 was significantly different between fibroadenoma, benign phyllodes and malignant phyllodes tumor. (Table 3 \& figure 3)

Stromal expression of Ki-67 was significantly higher in malignant phyllodes as compared to benign phyllodes and fibroadenoma. Epithelial expression of Ki-67 was negative in all malignant phyllodes cases while positive epithelial Ki-67 expression was seen in 56\% of fibroadenoma and $33 \%$ of benign phyllodes tumor. (Table 3, figure 3 ) 
Table: 1 Age Distribution.

\begin{tabular}{|c|c|c|c|c|}
\hline Age group (years) & $\begin{array}{c}\text { No of Fibroadenoma } \\
\text { cases }\end{array}$ & $\begin{array}{c}\text { No of Benign } \\
\text { Phyllodes cases }\end{array}$ & $\begin{array}{c}\text { No of Malignant } \\
\text { Phyllodes cases }\end{array}$ & Total \\
\hline $\mathbf{1 0 - 2 0}$ & $20(66.67 \%)$ & $01(6.67 \%)$ & $02(40 \%)$ & 23 \\
\hline $\mathbf{2 1 - 3 0}$ & $08(26.67 \%)$ & $08(53.33 \%)$ & $02(40 \%)$ & 18 \\
\hline $\mathbf{3 1 - 4 0}$ & $02(6.66 \%)$ & $05(33.33 \%)$ & $01(20 \%)$ & 09 \\
\hline $\mathbf{> 4 1}$ & $0(0 \%)$ & $01(6.67 \%)$ & $0(0 \%)$ & 01 \\
\hline
\end{tabular}

Table: 2 CD-10 Expression.

\begin{tabular}{|c|c|c|c|}
\hline $\begin{array}{c}\text { CD-10 expression in } \\
\text { stroma }\end{array}$ & No of fibroadenoma cases & $\begin{array}{c}\text { No of benign phyllodes } \\
\text { cases }\end{array}$ & $\begin{array}{c}\text { No of malignant phyllodes } \\
\text { cases }\end{array}$ \\
\hline Negative $(<30 \%)$ & $29(96.66 \%)$ & $11(73.33 \%)$ & $3(60 \%)$ \\
\hline Positive $(>30 \%)$ & $01(3.33)$ & $04(26.67 \%)$ & $02(40 \%)$ \\
\hline Total & 30 & 15 & 05 \\
\hline
\end{tabular}

*Chi square test

Table 3: P-53 and Ki-67 Expression.

\begin{tabular}{|c|c|c|c|c|c|c|c|c|}
\hline & & \multicolumn{2}{|c|}{ Fibroadenoma } & \multicolumn{2}{|c|}{ Benign Phyllodes } & \multicolumn{2}{|c|}{ Malignant Phyllodes } & \multirow{2}{*}{ P Value } \\
\hline & & $<20 \%$ & $>20 \%$ & $<20 \%$ & $>20 \%$ & $<20 \%$ & $>20 \%$ & \\
\hline \multirow{2}{*}{ P-53 } & Stroma & $\begin{array}{c}28 \\
(93.33 \%)\end{array}$ & $02(6.67 \%)$ & $\begin{array}{c}14 \\
(93.33 \%)\end{array}$ & $01(6.67 \%)$ & $02(40 \%)$ & $03(60 \%)$ & 0.006 \\
\hline & Epithelium & $\begin{array}{c}13 \\
(43.33 \%) \\
\end{array}$ & $\begin{array}{c}17 \\
(56.67 \%)\end{array}$ & $\begin{array}{c}11 \\
(73.33 \%)\end{array}$ & $\begin{array}{c}04 \\
(26.67 \%)\end{array}$ & $05(100 \%)$ & $0(0 \%)$ & 0.021 \\
\hline \multirow{2}{*}{ Ki-67 } & Stroma & $30(100 \%)$ & $0(0 \%)$ & $\begin{array}{c}13 \\
(86.67 \%)\end{array}$ & $\begin{array}{c}02 \\
(13.33 \%)\end{array}$ & $01(20 \%)$ & $04(80 \%)$ & 0.000 \\
\hline & Epithelium & $\begin{array}{c}13 \\
(43.33 \%)\end{array}$ & $\begin{array}{c}17 \\
(56.67 \%)\end{array}$ & $\begin{array}{c}10 \\
(66.67 \%)\end{array}$ & $\begin{array}{c}05 \\
(33.33 \%)\end{array}$ & $05(100 \%)$ & $0(0 \%)$ & 0.037 \\
\hline
\end{tabular}

*Chi square test

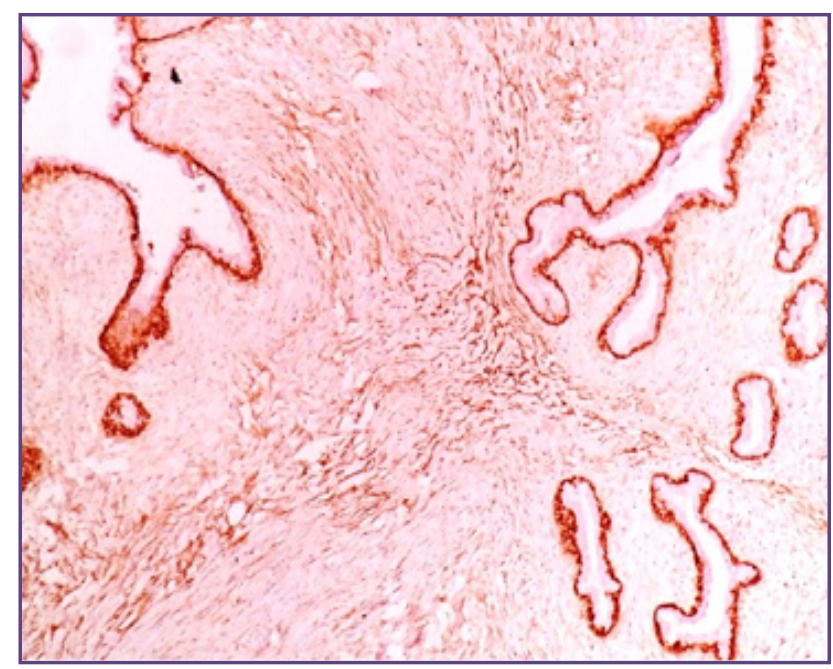

Fig. 1: Photomicrograph of Fibroadenoma showing cytoplasmic positivity with CD-10. $(>30 \%$ of tumor stromal cells positive). [ DAB, 100X].

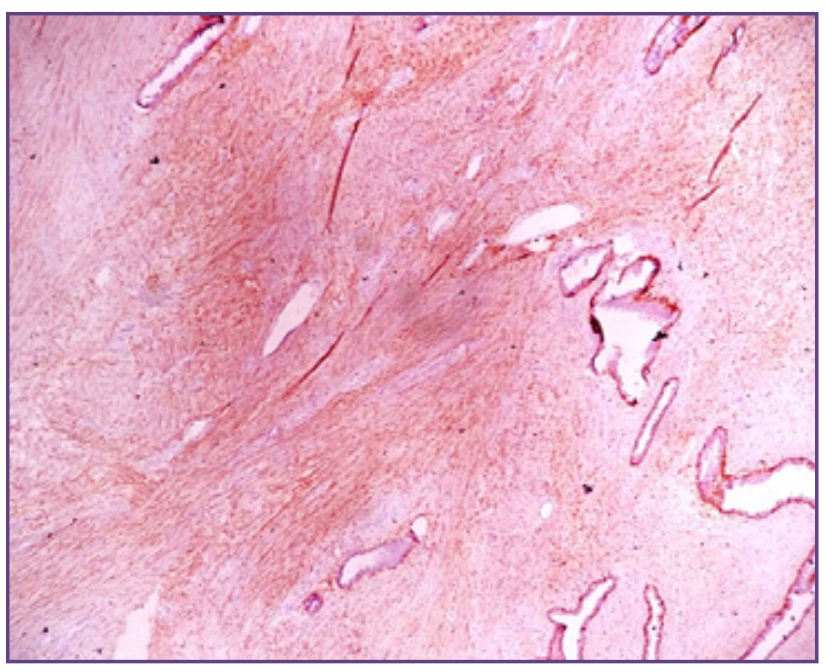

Fig. 2: Micrograph of Malignant Phyllodes tumor showing cytoplasmic positivity with CD-10. $(>30 \%$ of tumor stromal cells positive). [DAB, 40X]. 


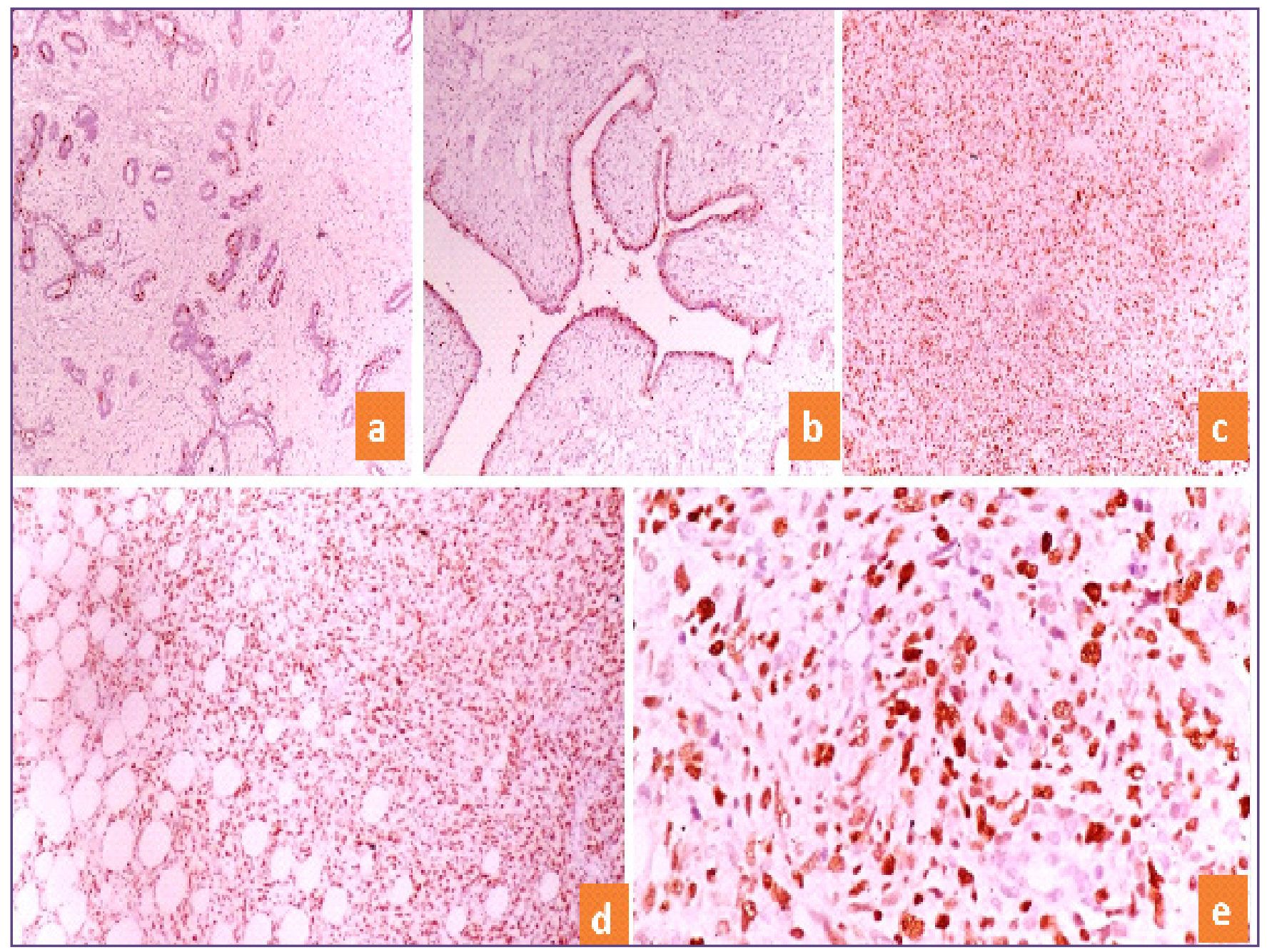

Fig. 3: a) Photomicrograph of Fibroadenoma showing nuclear positivity with Ki-67 immunostain. [DAB, 40X ] b) Photomicrograph of Benign Phyllodes tumor showing nuclear positivity with Ki-67 immunostain. [ DAB, 100X ] c) Photomicrograph of Malignant Phyllodes tumor showing nuclear positivity with Ki-67 immunostain. [ DAB, 40X ]d) Photomicrograph of Malignant Phyllodes tumor showing nuclear positivity with P-53 immunostain. [DAB, 100X ] e) Photomicrograph of Malignant Phyllodes tumor showing nuclear positivity with P-53 immunostain. [ DAB, 400X ].

\section{Discussion}

The study was conducted at a tertiary care hospital in North India. Total 50 cases including 30 cases of fibroadenoma, 15 cases of benign phyllodes and 5 cases of malignant phyllodes tumor were included in this study.

The age of patients in our study ranged from 14 to 55 years. The mean age of patients of fibroadenoma was $20.5 \pm 5.19$ $($ mean $\pm \mathrm{SD})$ years. Maximum number of patients were in the age group of 10-20 yrs. (66.67\%) followed by an age range between $21-30$ years $(26.67 \%)$. Puri $\mathrm{V}$ et $\mathrm{al}^{[13]}$ conducted a study with 50 cases of fibroadenoma. The mean age of patients in their study was 20 years and the majority of subjects were in the age group of 16-25 years. Tse GM et al ${ }^{[14]}$ studied 33 patients of fibroadenoma whose age ranged from 20-58 years with a mean age of 35 years.

In our study the mean age of benign phyllodes tumor cases was $29.3 \pm 7.79$ (mean $\pm \mathrm{SD}$ ) years. Maximum number of patients were in the age group of 21-30 yrs. (53.33\%) followed by an age range between $31-40$ years $(33.33 \%)$. Ibrahim WS et al ${ }^{[15]}$ conducted a study in the 24 cases of benign phyllodes tumors. The mean age of patients in their study was $32.5 \pm 10.7$ years and the age ranged from 1755 years. Surender Ket al ${ }^{[16]}$ studied 18 patients of benign phyllodes tumor. The mean age of patients in their study was 32.37 years with the range between 13-55 years. Kim CJ et al ${ }^{[17]}$ conducted a study in the 8 cases of benign phyllodes tumors. The mean age of patients in their study was 37.4 years and the age ranged from $24-45$ years. 
In our study the mean age of malignant phyllodes tumor cases was $22.2 \pm 5.63$ (mean $\pm \mathrm{SD}$ ) years. Maximum number of patients were in the age group of 21-30 yrs. (40\%) followed by an age range between 31-40 years (20\%). Chan YJ et a ${ }^{[18]}$ conducted a study in the 13 cases of malignant phyllodes tumor. The mean age of patients in their study was 32.5 years and the age ranged from 27-62 years. Kim CJ et $\mathrm{al}^{[17]}$ conducted a study in the 7 cases of malignant phyllodes tumors. The mean age of patients in their study was 34.1 years and the age ranged from 23-57 years.

\section{CD-10 Expression}

In our study CD-10 expression in all cases was evaluated using a semiquantitative method in the stroma. The positive cells were categorized into two subgroups: $<1=$ Negative ( $<30 \%$ of cells showing positivity); $2=$ positive $(>30 \%$ of cells showing positivity). Out of the 30 fibroadenoma cases only one case $(3.33 \%)$ showed positive CD10 expression, 29/30 (96.66\%) cases showed negative CD10 expression. In benign phyllodes tumor $4 / 15(26.67 \%)$ cases showed positive expression, $11 / 15(73.33 \%)$ showed negative for CD 10 expression. In cases of malignant phyllodes tumor $2 / 5(40 \%)$ cases showed positive expression, $3 / 5(60 \%)$ were negative for CD 10 expression. In our study no statistically, significant difference was noted in the stromal expression of CD 10 between cases of fibroadenoma, benign phyllodes and malignant phyllodes tumor. ( $\mathrm{p}=$ 0.097)

Puri $\mathrm{V}$ et $\mathrm{al}^{[13]}$ studied the stromal CD 10 expression in fibroadenoma, benign and malignant phyllodes. They found that none of the cases of fibroadenoma $(0 / 50)$ showed stromal CD10 expression. Positive stromal CD 10 expression was seen in 11/16 cases of benign phyllodes tumor and $3 / 3$ cases of malignant phyllodes tumor. Contrary to our study there was a statistically significant trend of increasing CD10 stromal expression with increasing degree of malignancy $(\mathrm{p}=0.001)$.

Tse GM et $\mathrm{al}^{[14]}$ studied the stromal expression of CD10 in 33 fibroadenoma, 102 benign phyllodes and 28 malignant phyllodes tumours . They concluded that only 1 of the 33 fibroadenoma cases stained positively for CD10 in the stromal cells. Six of the 102 benign phyllodes tumor cases were positive, and 14 of the 28 malignant cases were positive. Contradictory to our study there was a significant increase in CD10 expression in the stromal cells as the lesions progressed from fibroadenomas and benign phyllodes tumors to malignant phyllodes tumours $(p=0.001)$.
Ibrahim WS et al ${ }^{[15]}$ studied stromal expression in 24 cases of benign phyllodes tumors and 5 cases of malignant phyllodes tumors. They concluded that among benign phyllodes tumors, four cases (16.7\%) showed positive CD10 reactivity, distributed as three (12.5\%) weakly stained and only one (4.2\%) strongly stained, while 20 cases were negatively stained for CD10 (83.3\%). As for cases of malignant phyllodes tumors, one case $(20 \%)$ was weakly stained and three $(60 \%)$ were strongly stained, while the remaining one $(20 \%)$ was $\mathrm{CD} 10$ negative $(\mathrm{P}<0.0001)$.

Dissimilar to our study Al-Masri Met $\mathrm{al}^{[19]}$ also showed a significantly increasing trend $(\mathrm{P}<0.01)$ of CD10 positivity from benign to malignant phyllodes tumor. CD10 positivity was seen in $82.4 \%$ of malignant PT, $60 \%$ of borderline PT and $43.8 \%$ of benign PT.

\section{P-53 Expression}

In our study P-53 expression in all cases was evaluated using a semiquantitative method in the epithelium and stroma. The percentage of positive cells was categorized into two subgroups: $0=<20 \% ; 1=>20 \%$

In the epithelium, out of 30 cases of fibroadenoma, 17 cases ( $56.67 \%$ ) showed $\mathrm{P}-53$ positivity in $>20 \%$ of epithelial cells while 13 cases (43.33\%) showed P-53 expression in $<20 \%$ of epithelial cells. Out of 15 cases of benign phyllodes tumor, 04 cases $(26.67 \%)$ showed $\mathrm{P}-53$ positivity in $>20 \%$ of epithelial cells while 11 cases $(73.33 \%)$ showed P-53 expression in $<20 \%$ of epithelial cells. All cases of malignant phyllodes tumor, 5/5 (100\%) showed P-53 expression in $<20 \%$ of epithelial cells. Therefore, in our study a significant increase in epithelial expression of p53 was seen from benign to malignant cases $(p=0.021)$.

In the stroma $2 / 30$ cases $(6.67 \%)$ of fibroadenoma showed P-53 positivity in $>20 \%$ of stromal cells while 28 cases (93.33\%) showed P-53 expression in $<20 \%$ of stromal cells. Out of 15 cases of benign phyllodes tumor only 1 case (6.67\%) showed P-53 positivity in $>20 \%$ of stromal cells while 14 cases $(93.33 \%)$ showed P-53 expression in $<20 \%$ of stromal cells. Out of 5 cases of malignant phyllodes tumor 03 cases $(60 \%)$ showed $\mathrm{P}-53$ positivity in $>20 \%$ of stromal cells while 02 cases ( $40 \%$ ) showed P-53 expression in $<20 \%$ of stromal cells. Stromal expression of p53 was significantly higher in malignant phyllodes as compared to fibroadenoma and benign phyllodes $(\mathrm{p}=0.006)$.

Kucuk U et al ${ }^{[20]}$ studied the stromal and epithelial expression in 17 benign phyllodes and 9 malignant phyllodes tumours. In the benign group, the p53 positivity was $<20 \%$ in 15 cases and $21-42 \%$ in two cases. In the malignant group, the $\mathrm{p} 53$ positivity was $>41 \%$ in five cases, $21-40 \%$ in three cases and $<20 \%$ in one case. In concordance with our 
study, stromal p53 expression in the malignant PTs were shown to be significantly higher than that in the benign ones $(\mathrm{P}<0.001)$

Chan YJ et al ${ }^{[18]}$ studied 50 benign phyllodes and 13 malignant phyllodes tumours. In agreement with our study the stromal p53 expression showed a significant difference between benign and malignant lesions. Within the group of benign lesions, 5 out of $50(10 \%)$ tumors had p53 expression $>10 \%$, whereas nine out of $13(69 \%)$ malignant tumors revealed p53 expression $>10 \%(\mathrm{p}<0.005)$.

Another study done by Feakins RM et $\mathrm{al}^{[21]}$ who studied 13 malignant and 27 benign phyllodes tumours found no evidence of significant p53 expression in fibroadenomas or in benign phyllodes tumours, but demonstrated high level of expression in $38 \%$ of malignant tumours. Their data also showed that high level p53 expression was confined to stromal cells, with only low levels of expression found in the epithelium of five tumours.

Kim CJ et al ${ }^{[17]}$ studied 8 benign, 7 malignant phyllodes tumours. Cases of fibroadenoma were taken as controls. In agreement with our study stromal p53 expression was significantly increased in malignant lesions as compared to benign phyllodes tumour and fibroadenoma ( $p<0.005)$. The epithelial components of both benign and malignant cases showed completely negative staining to p53 protein. Gatalica $\mathrm{Z}$ et al ${ }^{[22]}$ studied $\mathrm{p} 53$ protein expression in 25 cases of phyllodes tumours histologically classified as either malignant (12 cases) or benign (13 cases). The stromal expression of p53 was more frequently observed in tumors that were histologically diagnosed as malignant (8/12) than benign (1/13). Similar to our study this difference was statistically significant $(\mathrm{p}=0.002)$. Kleer $\mathrm{CG}$ et $\mathrm{al}^{[23]}$ also analysed p53 immunoreactivity in the epithelial and stromal components of phyllodes tumour. The pattern of immunostaining was confined almost exclusively to periductal stromal cells. The results were similar to our study showing a higher expression of p53 in malignant phyllodes as compared to benign phyllodes.

p53 expression seemed to be a unique feature of malignant phyllodes tumors, thereby, one of the most significant parameters for the differentiation of benign and malignant phyllodes tumors of the breast.

\section{Ki-67 Expression}

Ki-67 expression in all cases was evaluated using a semiquantitative method in the epithelium. The percentage of positive cells was categorized into two subgroups: $0=<20 \% ; 1=>20 \%$
Out of 30 cases of fibroadenoma, 17 cases $(56.67 \%)$ showed Ki-67 positivity in $>20 \%$ of epithelial cells while 13 cases $(43.33 \%)$ showed Ki-67 expression in $<20 \%$ of epithelial cells. Out of 15 cases of benign phyllodes tumor, 05 cases $(33.33 \%)$ showed $\mathrm{Ki}-67$ positivity in $>20 \%$ of epithelial cells while 10 cases $(66.67 \%)$ showed $\mathrm{Ki}-67$ expression in $<20 \%$ of epithelial cells. All cases of malignant phyllodes tumor, $5 / 5(100 \%)$ showed Ki-67 expression in $<20 \%$ of epithelial cells. Therefore in our study a significant increase in epithelial expression of $\mathrm{Ki}-67$ was seen from benign to malignant cases $(\mathrm{p}=0.037)$.

In the stroma $30 / 30$ cases $(100 \%)$ of fibroadenoma showed $\mathrm{Ki}-67$ expression in $<20 \%$ of stromal cells. Out of 15 cases of benign phyllodes tumor, 02 case $(13.33 \%)$ showed Ki-67 positivity in $>20 \%$ of stromal cells while 13 cases (86.67\%) showed Ki-67 expression in $<20 \%$ of stromal cells. Out of 5 cases of malignant phyllodes tumour, 04 cases $(80 \%)$ showed Ki-67 positivity in $>20 \%$ of stromal cells while 1 cases (20\%) showed Ki-67 expression in $<20 \%$ of stromal cells. Stromal expression of Ki-67 was significantly higher in malignant phyllodes as compared to fibroadenoma and benign phyllodes $(\mathrm{p}=0.000)$.

Kocova L et $\mathrm{al}^{[24]}$ studied 8 malignant phyllodes tumour, 29 benign phyllodes tumour and 20 breast fibroadenomas. Their data indicated that there are statistically significant differences in stromal expression of $\mathrm{Ki}-67$ between histologically benign and malignant phyllodes tumours $(p=0.001)$, between benign phyllodes tumour and fibroadenoma $(\mathrm{p}=0.01)$, and between malignant phyllodes tumour and fibroadenoma $(\mathrm{p}=0.001)$. The epithelium expression of $\mathrm{Ki}-67$ was not included in the study.

Chan YJ et $\mathrm{al}^{[18]}$ studied 50 benign phyllodes and 13 malignant phyllodes tumors. Eleven out of $13(85 \%)$ malignant tumors and 8 out of $50(16 \%)$ benign tumors showed increased stromal Ki-67 expression> 10\%. Therefore similar to our study stromal expression of Ki 67 was significantly increased in malignant phyllodes tumour as compared to benign phyllodes tumor.

In the study done by Kucuk $\mathrm{U}$ et $\mathrm{al}^{[20]}$ all the benign phyllodes tumors (17/17) showed Ki-67 positivity in less than $10 \%$ of the stromal cells. But, in the stroma of the malignant tumors, Ki-67 was $<10 \%$ in $4 / 10$ cases and $>$ $10 \%$ in $5 / 9$ cases. In concordance with our study stromal Ki-67 expression in malignant tumors was significantly higher than that in the benign tumors $(\mathrm{P}<0.001)$. However contrary to our study the epithelial $\mathrm{Ki}-67$ expression ratios did not show a significant difference between the benign and malignant groups. 


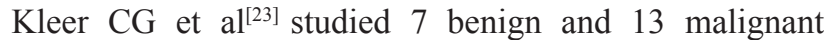
phyllodes tumour. Immunohistochemical staining revealed nuclear localization of Ki-67 in all groups of tumors in the epithelial and in the stromal cells. Similar to our study, analysis of the Ki-67 expression showed a significant difference between benign and malignant tumors $(\mathrm{P}<$ 0.012). Another study showed that malignant phyllodes tumour had a significantly higher proportion of Ki-67 expression as compared to its benign counterpart ( $\mathrm{p}<$ 0.01). ${ }^{[22]}$

\section{Conclusion}

On conclusion, both Ki-67 and P-53 showed a significantly increasing expression from fibroadenoma to benign phyllodes to malignant phyllodes tumor. However, in the present study the difference in expression of CD-10 was insignificant among fibroadenoma, benign phyllodes and malignant phyllodes tumor.

\section{Acknowledgements}

None

\section{Funding}

None

\section{Competing Interests}

None declared

\section{Reference}

1. World Health Organization. Histological typing of breast tumours.International. Histological Classification of Tumors. 2nd ed. Geneva, Switzerland: WHO; 1981.

2. Tan P, Tse G, Lee A. Fibroepithelial Tumours. In: Lakhani S, Ellis I, Schnitt S, Tan P, van de Vijver M, ed. by. WHO Classification of Tumours of the Breast. 4th ed. Lyon: IARC; 2012. p. 142-143.

3. Cole P, Elwood JM, Kaplan SD. Incidence rates and risk factors of benign breast neoplasms. American journal of epidemiology. 1978 Aug 1;108(2):112-20.

4. Fiks A. Cystosarcoma phyllodes of the mammary glandmüller's tumor. Virchows Archiv A. 1981 May 1;392(1):1-6.

5. Tan BY, Acs G, Apple SK, Badve S et al. "Phyllodes tumours of the breast: a consensus review.". Histopathology. 68 (1): $5-21$.

6. Velazquez EF, Yancovitz M, Pavlick A, Berman R et al. Clinical relevance of neutral endopeptidase (NEP/CD10) in melanoma. Journal of translational medicine. 2007 Dec;5(1):2.

7. Cohen AJ, Bunn PA, Franklin W, Magill-Solc C et al. Neutral endopeptidase: variable expression in human lung, inactivation in lung cancer, and modulation of peptide-induced calcium flux. Cancer research. 1996 Feb 15;56(4):831-9.
8. Iwaya K, Ogawa H, Izumi M, et al. Stromal expression of CD10 in invasive breast carcinoma: a new predictor of clinical outcome. Virchows Arch 2002;440:589-93.

9. Lane DP. Cancer. p53, guardian of the genome. Nature. 1992 Jul 2;358(6381):15-6.

10. BatinacT, Gruber F, Lipozencic J, Zamolo-Koncar G, Stasic A, Brajac I. Protein p53-structure, function, and possible therapeutic implications. Acta Dermatovenerol Croat. 2003 Dec;11(4):225-30.

11. Scholzen T, Gerdes J (March 2000). "The Ki-67 protein: from the known and the unknown". J. Cell. Physiol. 182 (3): 311-22.

12. Rahmanzadeh $R$, Hüttmann $G$, Gerdes $J$, Scholzen $T$. Chromophore $\square$ assisted light inactivation of pKi $\square 67$ leads to inhibition of ribosomal RNA synthesis. Cell proliferation. 2007 Jun;40(3):422-30.

13. Puri V, Jain M, Mahajan G, Pujani M. Critical appraisal of stromal CD10 staining in fibroepithelial lesions of breast with a special emphasis on expression patterns and correlation with WHO grading. J Cancer Res Ther. 2016 Apr-Jun;12(2):667-70.

14. Tse GM, Tsang AK, Putti TC, Scolyer RA et al. Stromal CD10 expression in mammary fibroadenomas and phyllodes tumours. J Clin Pathol. 2005 Feb;58(2):185-9.

15. Ibrahim WS. Comparison of stromal CD10 expression in benign, borderline, and malignant phyllodes tumors among Egyptian female patients. Indian J Pathol Microbiol. 2011 Oct-Dec;54(4):741-4.

16. Surender K, Faraz A, Akshay A, SonkarAA et al. Diagnostic and prognostic role of stromal CD 10 and $\mathrm{Ki} 67$ in benign and malignant Phylloides tumor of breast. International Journal of Medical and Health Sciences. 2017;6(2):85-9.

17. Kim CJ, Kim WH. Patterns of p53 expression in phyllodes tumors of the breast--an immunohistochemical study. J Korean Med Sci. 1993 Oct;8(5):325-8.

18. Chan YJ, Chen BF, Chang CL, Yang TL, Fan CC. Expression of p53 protein and $\mathrm{Ki}-67$ antigen in phyllodes tumor of the breast. Journal-Chinese Medical Association. 2004 Jan;67(1):3-8.

19. Al-Masri M, Darwazeh G, Sawalhi S, Mughrabi A et al. Phyllodes tumor of the breast: role of CD10 in predicting metastasis. Annals of surgical oncology. 2012 Apr $1 ; 19(4): 1181-4$

20. Kucuk U, Bayol U, Pala EE, Cumurcu S. Importance of P53, Ki-67 expression in the differential diagnosis of benign/ malignant phyllodes tumors of the breast.Indian $\mathrm{J}$ Pathol Microbiol. 2013 Apr-Jun;56(2):129-34.

21. Feakins RM, Mulcahy HE, Nickols CD, Wells CA. p53 expression in phyllodes tumours is asso-ciated with histological features of malignancy but does not predict outcome. Histopathology. 1999 Aug;35(2):162-9. 
22. Bernstein L, Deapen D, Ross RK. The descriptive epidemiology of malignant cystosarcoma phyllodes tumors of the breast. Cancer. 1993 May 15;71(10):3020-4.

23. Cohn $\square$ Cedermark G, Rutqvist LE, Rosendahl I, Silfverswärd C. Prognostic factors in cystosarcoma phyllodes. A clinicopathologic study of 77 patients. Cancer. 1991 Nov 1;68(9):2017-22.

24. Kočová L, Skálová A, Fakan F, Roušarová M. Phyllodes tumour of the breast: immunohistochemical study of 37 tumours using MIB1 antibody. Pathology-Research and Practice. 1998 Jan 1;194(2):97-104.

*Corresponding author:

Dr Namrata Sarin, Department of Pathology, North Delhi Municipal Corporation Medical College and Hindu Rao Hospital, Delhi, India

Phone: +91 011-23905652

Email: drnamrata50@gmail.com

Financial or other Competing Interests: None.

Date of Submission : 28/09/2020

Date of Revision : $: 20 / 12 / 2020$

Date of Acceptance : 22/12/2020

Date of Publication : 30/01/2021 